\title{
Disputas políticas en un territorio de frontera. La incorporación de la Provincia Oriental a la monarquía bragantina ${ }^{1}$
}

\author{
Laura Martínez Renau ${ }^{2}$
}

Recibido: 17 de julio de 2020 / Aceptado: 26 de octubre de 2020

Resumen. El presente trabajo se centra en analizar los años de 1820-1823 en la ciudad de Montevideo. La capital de la Provincia Oriental fue ocupada en 1817 por las tropas portuguesas y en 1821 formalizó - mediante un Congreso Extraordinario - la incorporación del territorio a la monarquía portuguesa de los Braganza. Es por ello que, cuando triunfó la segunda revolución liberal en España en 1820 y la primera portuguesa, en el mes de agosto de ese mismo año, la provincia, convertida en la Cisplatina, se adhirió al movimiento constitucional portugués. A lo largo de estas páginas veremos cómo fue el proceso de incorporación del territorio a la monarquía bragantina, y cómo se vivió en Montevideo la disputa entre el rey João VI y el príncipe regente don Pedro cuando este último planificó la declaración de independencia del Brasil a lo largo del año de 1822.

Palabras clave: Revolución; liberalismo; independencia; Cisplatina; Montevideo; siglo XIX.

\section{[en] Political Disputes in a Frontier Territory. The Incorporation of the Eastern Province into the Brigantine Monarchy}

\begin{abstract}
This article focuses on an analysis of the years 1820-1823 in the city of Montevideo. The capital of the Eastern Province was occupied by Portuguese troops in 1817 and formally incorporated in 1821, by means of an Extraordinary Congress, into the territory of the Portuguese Braganza Monarchy. Because of this, when the Second Liberal Revolution triumphed in Spain in 1820, and the first Portuguese one in August of the same year, the province joined the Portuguese constitutionalist movement and became the Cisplatine Province. In these pages we will see how the process of incorporation into the Brigantine Monarchy took place and how Montevideo experienced the disputes between King João VI and the Prince Regent, while the latter was planning the Brazilian declaration of independence throughout the year 1822 .
\end{abstract}

Keywords: Revolution; Liberalism; Independence; Cisplatine; Montevideo; 19th Century.

Sumario. 1. La Banda Oriental, de la monarquía borbónica a la bragantina. 2. Las revoluciones liberales a una y otra orilla del Atlántico. 3. La formalización de una incorporación ¿inesperada? 4. 1822. Un año controvertido. 5. A modo de conclusión. 6. Referencias bibliográficas.

Cómo citar: Martínez Renau, L. (2021) "Disputas políticas en un territorio de frontera. La incorporación de la Provincia Oriental a la monarquía bragantina", en Revista Complutense de Historia de América 47, 89-110.

\footnotetext{
1 Este artículo se inscribe en el proyecto financiado por MINECO, "Entre dos mundos. Historia parlamentaria y culturas políticas en los años del Trienio Liberal (1820-1823)" (HAR2016-78769P).

2 Universitat de València [España]

E-mail: laura.Martinez-Renau@uv.es
} 


\section{La Banda Oriental, de la monarquía borbónica a la bragantina}

Acorde con sus territorios vecinos, el inicio del siglo XIX en la orilla oriental del Río de la Plata supuso el comienzo de décadas de incertidumbre, de cambios y de enfrentamientos tanto entre las facciones locales como en la diplomacia internacional. Además del interés que suscita el estudio de los efectos que las revoluciones liberales tuvieron en territorio iberoamericano, resulta interesante atender a cómo, en la Banda Oriental, la transición y adaptación de los principios liberales se dieron en un ambiente de inestabilidad política y de conflictividad social. A pesar de que esta situación no es exclusiva de esta provincia, sí que dispone de una característica que la diferencia del resto de territorios que en este contexto de revolución se independizaron de la monarquía española: la ciudad de Montevideo fue ocupada por las tropas portuguesas en 1817 y se mantuvo bajo la gobernación lusa primero y brasileña después hasta la declaración de independencia en el año 1828.

La rivalidad entre la monarquía borbónica y la bragantina por la ocupación de la orilla oriental del Río de la Plata remonta a siglos anteriores. La fundación portuguesa de la ciudad de Colonia del Sacramento en 1680 puso en alerta a las autoridades españolas que, como respuesta, levantaron en la década de 1720 la ciudad de Montevideo $^{3}$. Ya en el Ochocientos y en un contexto internacional agitado (el inicio en España de la revolución liberal, la invasión napoleónica, el inicio de la guerra en la península y el establecimiento de la Corte de los Braganza en Rio de Janeiro) el regente João encontró el pretexto idóneo para intervenir en la Banda Oriental. La monarquía de los Braganza realizó dos incursiones en la provincia. La primera de ellas en 1811, cuando el virrey de Montevideo Francisco Javier Elío, fiel a Fernando VII, vio cómo las tropas revolucionarias de la Junta porteña y los orientales en armas, lideradas por el general en jefe José Rondeau y por Artigas como segundo jefe, amenazaban la capital iniciando un sitio a la ciudad de Montevideo ${ }^{4}$. Pidió entonces ayuda a la Corte portuguesa, que instalada en Rio de Janeiro desde 1808 envió en el mes de julio lo que calificó de un "ejército pacificador". El armisticio que puso fin a este primer sitio fue firmado en octubre de 1811, al año siguiente, las tropas portuguesas abandonaron el territorio 5 .

Unos años más tarde, en 1816, la Provincia Oriental se encontraba gobernada por el general Artigas. Sus ideas federales y sus posturas revolucionarias sobre el igualitarismo y los derechos populares alertaron tanto al gobierno en Buenos Aires como a la monarquía bragantina en Rio de Janeiro ${ }^{6}$. João VI organizó un ejército que se dirigiría al territorio, bajo la justificación de que la revolución latente en el Río de la Plata amenazaba sus territorios americanos. Fue entonces cuando se produjo la segunda intervención portuguesa, diferente de la anterior, porque en esta ocasión el objetivo era ocupar la ciudad de Montevideo y controlar la totalidad de la provincia. La División de Voluntarios Reales fue creada en Portugal y constaba de 4.929 hombres que dirigidos por el general Carlos Federico Lecor - que en 1818 recibió el título nobiliario de Barón de la Laguna - cruzaron la frontera con la Provincia Oriental a mediados de 1816. En el mes de enero de 1817 llegaron a las puertas de Montevideo 7.

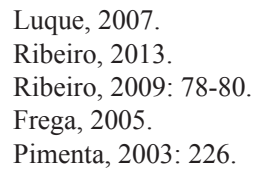


Fernando VII condenó la entrada portuguesa en la capital oriental y la denunció ante las monarquías legitimistas europeas. Ante la protesta del monarca español, la familia real lusa justificó la ocupación como temporal. Es decir, la presencia de las tropas en la Provincia Oriental se debía únicamente a su estado insurreccionado, la motivación que llevó a João VI a intervenir sería el miedo a que la inestabilidad y la revolución se extendiese al Brasil. Una vez fuese pacificado el territorio, la monarquía lusa retiraría de la provincia a la División de Voluntarios Reales ${ }^{8}$.

Ahora bien, durante años, la familia real portuguesa había reclamado mediante la teoría de las fronteras naturales su derecho a ampliar los dominios americanos hasta el Río de la Plata, una demanda, además, arraigada y defendida también por la opinión pública' ${ }^{9}$ En estos años se escribió un documento en el que se detallaba el contexto político rioplatense y la rivalidad bonaerense, artiguista y de la monarquía borbónica por controlar y gobernar la Provincia Oriental. Su autor no firmó el oficio con su nombre completo $^{10}$, pero su escritura cumplía la orden del príncipe regente João por la que pedía "que diga mi parecer sobre el estado actual de nuestra situación política y militar al respecto de las Provincias del Río de la Plata". Aunque no está fechado, podemos intuir que fue escrito entre los años 1815 o 1816, en primer lugar, por los acontecimientos que se narran en él: hace alusión al Congreso de Viena, a la coyuntura política europea, a las facciones políticas bonarenses, así como hablaba también de Artigas de quién decía que "ha obtenido una reputación que no merece"11. En segundo lugar, el texto hace alusión al príncipe regente João como Su Alteza Real. João VI heredó la Corona en el mes de marzo de 1816, por lo que el oficio debe ser anterior a su coronación. En último lugar, y lo más relevante, el documento comenzaba del siguiente modo: "las ventajas que se pueden seguir al Brasil con la posesión de la margen oriental del Río de la Plata merecen más las vistas del gobierno de lo que mismo el recelo del nuevo sistema de aquellas provincias, o el cuidado filantrópico y pacificador de las mismas"12. Es, por tanto, anterior a la entrada lusa en la Provincia Oriental porque a lo largo de las páginas realizaba la defensa y planificación militar para la ocupación del territorio.

$\mathrm{Su}$ autor presentaba un panorama pesimista, en el que cualquier intento de negociación con las fuerzas que se disputaban la Provincia Oriental (Fernando VII, el gobierno de Buenos Aires y Artigas) sería frustrada bien por la ineptitud de sus autoridades, o bien por la inestabilidad gubernamental. De la monarquía borbónica señalaba, además, la incapacidad que había mostrado para imponerse a las revoluciones iniciadas en Hispanoamérica, apuntando que "la intriga hace nacer las revoluciones y solo las armas las acaban"13. Se trataba de una maniobra en la que planificaba cómo disputarle la orilla oriental del Río de la Plata al monarca español intentando que no ocurriese lo mismo que en 1811, que, a su parecer, supuso un gran gasto económico y militar portugués sin que la familia real lusa pudiese extraer beneficio. Por todo ello, proponía:

Hagamos todo por arrancarle una cesión formal de la provincia y plaza de Montevideo. Se deben hacer valer los servicios ya hechos a su causa tanto en Europa

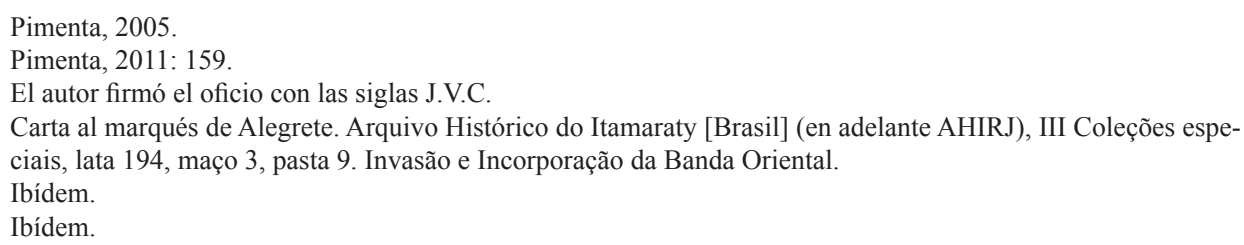


como en América y aquellos que nuestras tropas se pueden suministrar en la ocasión de su expedición al Río de la Plata, servicios que de cierto serán los decisivos en el resultado de sus esfuerzos ${ }^{14}$.

El texto terminaba con una advertencia al gobierno en Madrid: la posibilidad que tenía la Corte bragantina de fomentar la independencia de las provincias del Río de la Plata "cuando no se nos realice nuestra pertenencia". Su autor no esperaba que Fernando VII cediera el territorio, tras lo cual, insistía en que siempre que la "anarquía" continúe en el Río de la Plata, que la monarquía española no ponga medios para evitarlo y que "los Estados de SAR se vean amenazados de una fuerza armada, entonces todo el territorio conquistado por los ejércitos portugueses pertenecerá de propiedad y derecho a SAR y nunca restituidos como aconteció en $1812 " 15$. Esta última idea se repetía, como hemos podido ver, en distintas ocasiones a lo largo del documento. En él se insistía en que la entrada en la Provincia Oriental debía ser para conquistarla e incorporarla a los territorios portugueses, y no una intervención altruista en la que se invirtieran esfuerzos económico-militares sin poseer el territorio. Tras la presentación de la coyuntura política tanto rioplatense como europea, se detallaba la estrategia militar que debía seguir el ejército portugués para la ocupación de la plaza de Montevideo. A pesar de que el escrito se basaba en una opinión personal, muestra la preocupación bragantina por anexionarse la Provincia Oriental. También que el envío de un ejército que en enero de 1817 se encontraba a las puertas de la muralla montevideana no fue un acto espontáneo sino premeditado ${ }^{16}$.

De este modo, el general Carlos Federico Lecor, seguido por la División de Voluntarios Reales, entró triunfante en la ciudad de Montevideo el 20 de enero de 1817, aunque el control de la capital oriental no supuso el fin de la guerra contra el ejército artiguista en el resto de la provincia, que no terminó hasta 1820 . Se iniciaron así los años en los que la ciudad de Montevideo estuvo gobernada por las fuerzas portuguesas hasta 1824. En este año fue oficialmente incorporada al Imperio de Pedro I tras un conflicto bélico entre las tropas portuguesas e imperiales (1822-1823) por la declaración de independencia del Brasil. En 1828 concluyó la guerra entre las Provincias Unidas del Río de la Plata y el Brasil imperial y la provincia comenzó a constituir el nuevo Estado independiente.

A lo largo de las páginas que siguen me centraré en presentar la controversia que supuso la ocupación luso-brasileña de la Provincia Oriental en 1820, tanto a nivel local como internacional. Además, cabe situar su incorporación al Reino Unido de Portugal, Brasil y Algarve en un contexto histórico más amplio: el triunfo de las revoluciones liberales en la península i la instauración de sistemas políticos también liberales en los Estados iberoamericanos que habían declarado su independencia. Por ello, no podemos dejar de atender a cómo, en los primeros años veinte, no solamente se buscó la consolidación de un gobierno luso-brasileño en la ciudad de Montevideo, sino también que este fuese liberal.

Ibídem.

Ibídem.

16 El historiador João Paulo G. Pimenta muestra la controversia entre las verdaderas intenciones de la monarquía bragantina al ocupar la Provincia Oriental, y al mismo tiempo, la preocupación por no mostrarlas internacionalmente con la intención de evitar el conflicto con Fernando VII y la Santa Alianza. Pimenta, 2011. Véase también Pimenta, 2017. 


\section{Las revoluciones liberales a una y otra orilla del Atlántico}

Los años veinte inauguraron en la península un nuevo periodo constitucional. El pronunciamiento del general Riego en el mes de enero inició en España el conocido como Trienio Liberal ${ }^{17}$. El 9 de marzo, Fernando VII ${ }^{18}$ juró la Constitución que 8 años antes había sido proclamada en Cádiz, aunque el contexto en el que España volvía de nuevo a ser una monarquía constitucional era notablemente distinto al anterior: la amenaza napoleónica había terminado pero la Santa Alianza representaba un peligro para los gobiernos liberales que buscaban consolidarse en el sur de Europa. Además, los territorios hispanoamericanos que años antes habían proclamado su fidelidad a Fernando VII se encontraban ahora sumidos en guerras civiles.

La revolución liberal de Oporto comenzó unos meses después de la española, inspirados por esta última, el 24 de agosto de 1820 un heterogéneo grupo de militares, comerciantes, funcionarios de Estado y aristócratas daba inicio a un movimiento revolucionario conocido en la historiografía lusa como vintismo. El 15 de diciembre de 1820 la Junta Provisional do Governo Supremo do Reino publicó el Manifiesto de la Nación portuguesa a los soberanos y pueblos de Europa. En él desaprobaban las incursiones de las tropas portuguesas en los territorios de la América hispánica, alegando que fue la regencia de Lisboa la que asumió los costes de las dos expediciones militares que en 1815 y 1817 envió un total aproximado de 5000 hombres en dirección a las campañas en el Plata ${ }^{19}$. Además, pedían que la Corte bragantina, establecida en Rio de Janeiro desde 1808 volviese a Lisboa, buscando atenuar lo que algunos historiadores han llamado la "inversión colonial"20, de este modo, la ciudad portuguesa se alzaría de nuevo como centro de poder. Ante la coyuntura y las exigencias de los revolucionarios portugueses se presentaban diversas alternativas en un escenario en el que todo era posible. El gabinete ministerial de la Corte portuguesa planteó diversas opciones. Que la familia real permaneciese en el Brasil, que volviese João VI o don Pedro a Lisboa — pero no ambos - y discutieron la conveniencia de ratificar el constitucionalismo, o si por el contrario, debía mantenerse el carácter absolutista de la monarquía ${ }^{21}$.

El debate sobre si la Corte debía regresar a Lisboa se amplió también a la prensa tanto europea como americana. En ese mismo año de 1820 se escribió en Rio de Janeiro un extenso texto, de autoría anónima aunque sus autores indicaban que no habían nacido "ni en Portugal ni en el Brasil". Parece que finalmente no se hizo público, pues en la hoja del archivo que indica la naturaleza del documento puede leerse: "copia de un impreso que no circuló”. Escrito en español y bajo el título "¿El rey y la familia de Braganza deberán en las actuales circunstancias volver a Portugal o permanecer más bien en el Brasil?"22 detallaba los motivos por los que João VI debía quedarse en Rio de Janeiro y tratar de mantener bajo su gobernación los territorios americanos. Del escrito pueden recogerse tres ideas. La primera de ellas era que, si

\footnotetext{
El libro de Alberto Gil Novales es una obra clásica para su estudio y profundización. Gil, 1980.

Sobre la figura de Fernando VII, véase: La Parra, 2018.

Pimenta, 2003: 352-353.

Sánchez, 2009.

Pimenta, 2003: 354-355.

22 ¿El Rey y la familia de Braganza deberán en las actuales circunstancias volver a Portugal o permanecer más bien en el Brasil? Rio de Janeiro, 1820. Archivo General de la Nación [Uruguay] (en adelante AGNM), fondo del Ex Archivo y Museo Histórico Nacional, caja 180, carpeta 9, documento 1.
} 
la Corte partía a Lisboa, penetrarían las ideas revolucionarias que triunfaban en la América hispana, lo que supondría una próxima declaración de independencia del Brasil. En segundo lugar, los ventajosos beneficios económicos que proporcionaba el Brasil frente al "imperio de tercer orden" como calificaban a Portugal. Consideraban que no existía reciprocidad en las ventajas que un territorio extraía del otro, pues Portugal presentaba una dependencia económica del Brasil, mientras que este no la tenía de la parte europea. En último lugar, si la familia real permanecía en Rio de Janeiro evitaría la propagación del ideario revolucionario, al contrario que, si se decidía por volver a Lisboa, donde estaría "en el centro del contagio"23. Este documento debe entenderse en el contexto de rivalidad entre las fuerzas liberales y antiliberales tanto en Europa como en Iberoamérica. Cabe destacar, además, la intencionalidad que sus autores mostraron de establecer un "cordón sanitario" entre el Brasil y sus vecinos insurreccionados, una de las características del pensamiento reaccionario de la época.

Mientras la Corte decidía su retorno a Lisboa o su permanencia en Rio de Janeiro, a lo largo del año de 1821 se formaron juntas de gobierno en distintas capitanías del Brasil que se adhirieron al movimiento constitucional luso. Lo hicieron incluso con anterioridad a que el rey João VI reconociese la instalación de las Cortes y jurase la Constitución pendiente de ser redactada por estas. Y de que anunciase su regreso a Lisboa, lo que comunicó finalmente el 26 de febrero de $1821^{24}$.

En consonancia con los territorios del Brasil, también la División de Voluntarios Reales, establecida en la ciudad de Montevideo desde 1817 reaccionó al liberalismo promulgado por las Cortes lisboetas. La Gaceta de Buenos Ayres informaba de los acontecimientos en los que la noche del 20 de marzo de 1821 tres regimientos comandados por el general Antonio José Claudino de Oliveira Pimentel, amanecieron en la plaza de Montevideo, "hicieron venir a su posición al general Lecor y lo obligaron a jurar la Constitución que ha de formarse y regir en Portugal" 25 . Lecor mostró reticencia ante el acto de los miembros de la División. Su primera respuesta fue alegar que estaba enfermo para no presentarse ante las tropas en la plaza, pero se le ordenó de nuevo que se uniese. Insistió en su malestar, por lo que fue el secretario militar Flangini el que acudió a la plaza. No convenció, la División contestó con un aviso: "si no venía en el acto el general, las tropas iban a nombrar a otro"26. El capitán general Lecor no fue la única autoridad que a una y otra orilla del Atlántico se excusaba en no poder acudir a una demostración de estas características. Contamos con otros ejemplos que bien por oposición política al constitucionalismo o bien por motivos e intereses personales, se oponían a formalizar su adhesión al nuevo régimen liberal.

$\mathrm{Al}$ igual que en otras zonas del Brasil — como Bahía y Pernambuco ${ }^{27}$ —, también en Montevideo se formó un Consejo Militar que se instaló, presidido por Lecor, el día 21 de marzo de 1821. El día 27 los comandantes y oficiales superiores juraron fidelidad a la futura Constitución portuguesa tras lo cual enviaron representantes tanto a Río de Janeiro como a las Cortes lisboetas con tal de informar de su apertura ${ }^{28}$. Como podemos reparar, refieren constantemente a una Carta Magna portuguesa que fue san-

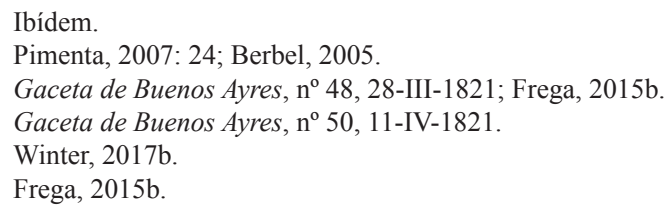


cionada al año siguiente, en 1822. Podría plantearse que realizaron el acto de juramento, de manera provisional, a la Constitución gaditana de 1812, la cual tuvo una notable influencia en el liberalismo portugués de principios de los años veinte y fue, de hecho, aclamada en el Brasil hasta que entrase en vigor la Constitución liberal lusa ${ }^{29}$.

No obstante, cabe apuntar que el cabildo de Montevideo no se reunió durante el mes de marzo, y no lo hizo hasta mediados del mes de abril. La jura a la futura Constitución portuguesa y la adhesión al sistema constitucional se realizó desde las autoridades militares, pero no por los representantes civiles de la capital. El reconocimiento del régimen liberal portugués por parte de estos últimos se llevó a cabo meses después, cuando el Congreso Cisplatino, celebrado entre los meses de julio y agosto de 1821, decretó la incorporación formal a la monarquía liberal portuguesa. En ello me detendré más adelante, pero hago referencia para reparar en la encrucijada en la que se encontraba la ciudad de Montevideo. João VI insistía en el carácter temporal de la ocupación de la Provincia Oriental. La adhesión al movimiento constitucional portugués por parte de los miembros del cabildo o la población montevideana supondría la incorporación formal del territorio al Reino Unido de Portugal, Brasil y Algarve - lo que el monarca no estaba dispuesto a reconocer-, especialmente, teniendo en cuenta, además, que en el año 1821 tanto Fernando VII como João VI eran monarcas constitucionales.

Durante estos primeros años de la ocupación portuguesa de la Provincia Oriental (1817-1821) llegaron a Montevideo rumores continuos sobre la posibilidad de que la provincia fuese atacada bien por el gobierno de Buenos Aires o bien por la monarquía hispánica con la finalidad de expulsar a los portugueses y ejercer el control político de la provincia. Llegaban informaciones sobre la salida de una expedición que desde Cádiz estaría destinada al Río de la Plata. Como no se tenía más información sobre ellas, las autoridades montevideanas pensaron, incluso, que las noticias eran falsas, y que la finalidad de propagarlas era para mantener viva la oposición que desde la campaña se ejercía a las fuerzas portuguesas: "acaso estaría ya la provincia en un perfecto sosiego si no fuera por la influencia de estos tristes rumores sobre la opinión de sus habitantes" ${ }^{\prime 30}$. El 14 de septiembre de 1819 se publicó en Rio de Janeiro la noticia sobre la preparación de seis naves, seis fragatas y 18.000 hombres que España enviaría al Río de la Plata, ante lo cual, se trazó un plan defensivo y se movilizó a las tropas para organizarse ante un posible ataque no solamente a Montevideo sino también a la Corte bragantina en Rio de Janeiro ${ }^{31}$. Este ejército no llegó a salir de la ciudad gaditana, pues sufrió una epidemia de fiebre amarilla. Fueron también estos hombres los que el día 1 de enero de 1820 se levantaron contra la monarquía absoluta de Fernando VII, dando inicio en España al Trienio Liberal.

El inicio del nuevo periodo constitucional español en 1820 reanimó en Madrid la esperanza de poder fomentar el acercamiento y la reconciliación entre el gobierno liberal español y los territorios hispanoamericanos. Con este fin, el conde de Casa

29 Historiadores como Márcia Berbel, Julio Sánchez Gómez y Ana Frega han señalado la importancia que la Constitución gaditana de 1812 tuvo en el movimiento liberal luso-brasileño y que estuvo incluso vigente provisionalmente en territorios del Reino Unido de Portugal, Brasil y Algarve. Berbel, 2008 y 2012; Sánchez, 2012; Frega, 2012.

30 Aviso de las autoridades montevideanas. Montevideo, 1818. AGNM, fondo de los Archivos Particulares, caja 319 , carpeta 1 , documento 88 .

31 Plan defensivo sobre el posible arribo de tropas al Río de la Plata. Rio de Janeiro, 1819. AGNM, fondo de los Archivos Particulares, caja 319, carpeta 1, documentos 114 y 115. 
Flores, ministro plenipotenciario español en Rio de Janeiro envió al cabildo y al consulado de Montevideo un manifiesto en el que animaba a las provincias rioplatenses a reincorporarse al nuevo régimen liberal iniciado en la península ${ }^{32}$. Además, se formó también una comisión formada por Manuel Herrera, Tomás de Comyn y Manuel Martín Mateo que llegó a Rio de Janeiro para encontrarse primero con el Conde de Casa Flores, pero cuyo destino era el Río de la Plata en un intento de promover un entendimiento con los gobiernos de esta zona ${ }^{33}$. No obstante, la comisión recibió negativas a desembarcar en Montevideo tanto desde la Corte portuguesa, que obstaculizó su llegada, como desde el gobierno de Buenos Aires, que no les permitía acercarse a los territorios del antiguo virreinato hasta que no fuese reconocida la independencia que las Provincias Unidas del Río de la Plata habían declarado el 9 de julio de $1816^{34}$. E1 7 de noviembre de 1820 Lecor envió un oficio a la Corte portuguesa agradeciendo su oposición a que los comisionados españoles llegasen a la capital oriental, pues desconfiaba de sus intenciones y señalaba que obedecían órdenes de "hacer cuanto esté a su alcance a fin de conseguir que las colonias españolas disidentes acepten de nuevo la obediencia a su antigua metrópoli bajo condiciones más extensas y beneficiosas para los americanos y en el caso de que todas sus diligencias sean en balde, declarar la independencia de las mismas colonias disidentes con cierta primacía y ventajas para España" 35 . Tanto la reacción de la Corte lusa al impedir que los tres comisionados pudiesen desembarcar en Montevideo como el escrito de Lecor contradicen la versión oficial portuguesa sobre su ocupación temporal de la Provincia Oriental, y muestran una intencionalidad que va más allá de la pacificación del territorio. La gobernación política de la provincia suponía controlar un espacio geoestratégico, privilegiado para el comercio, pues Montevideo contaba con un excelente puerto natural, la puerta de entrada y de salida de buques hacia la península. No obstante, en estos primeros años veinte aparecerán detractores a la presencia lusa en ella también en el interior del Reino Unido de Portugal, Brasil y Algarve. Algunos de los diputados en las Cortes lisboetas se posicionaron a favor del embarque de la División de Voluntarios Reales de Montevideo alegando especialmente dos razones. La primera, económica, hacía referencia al capital invertido en ella. La segunda buscaba un acercamiento con la monarquía borbónica para favorecer un acuerdo político-militar que permitiese defender la península, bajo el régimen liberal, de la amenaza de la Santa Alianza. El desalojo de la ciudad de Montevideo, punto de desencuentro entre Portugal y España, era crucial para que pudiesen restablecerse las relaciones ${ }^{36}$.

\section{La formalización de una incorporación ¿inesperada?}

El reconocimiento de la revolución liberal de Oporto por el monarca João VI y el inicio de las sesiones en las Cortes de Lisboa abrió el debate sobre qué procedimien-

32 Conde de Casa Flores. Correspondência expedida. Rio de Janeiro, 1820. Arquivo Histórico do Itamaraty de Rio de Janeiro [Brasil] (en adelante AHIRJ), III coleções especiais, lata 171, maço 6, pasta 4.

33 Frasquet, 2010; Martínez Riaza, 2011.

34 Frega, 2009: 19-63.

35 Carta de Lecor a la Corte en Rio de Janeiro. Montevideo, 1820. AGNM, fondo del Archivo de Juan Ernesto Pivel Devoto, caja 19, carpeta 58, documento del día 7 de noviembre de 1820.

36 Para profundizar en la apertura de las Cortes liberales de Lisboa y los debates de sus sesiones véase Berbel, 1998. 
to seguir en la Provincia Oriental, ¿debía mantenerse bajo la influencia portuguesa o debía la División de Voluntarios Reales desocupar Montevideo? El 16 de abril de 1821, días previos a que la Corte bragantina regresase a Europa, el ministro de negocios extranjeros y de guerra portugués, Silvestre Pinheiro Ferreira, envió a Lecor un extenso documento en el que detallaba las instrucciones para que se celebrase en Montevideo un Congreso Extraordinario cuyo fin era que sus diputados resolviesen el futuro político de la provincia. El ministro señalaba cuáles serían las opciones sobre las que debía debatirse: la unión formal al Brasil, la incorporación a cualquier otra provincia o Estado (entre las que se contemplaban las Provincias Unidas del Río de la Plata o España) o la constitución de un país independiente ${ }^{37}$. En este mismo documento, Silvestre Pinheiro Ferreira mostraba la firme convicción de que los diputados asistentes al Congreso decretarían esta última opción, tildándola de la "más probable" frente a la escasa posibilidad —en opinión del ministro- de que los representantes orientales se decidiesen por la unión al Reino del Brasil. No envió por escrito las instrucciones exactas que las autoridades portuguesas en la capital oriental debían seguir para la elección de los representantes y la convocatoria del Congreso, sin embargo, sí escribió indicaciones para ello que Lecor y Juan José Durán (intendente interino de la provincia) adaptaron a la realidad político-social de la provincia y especialmente, las modificaron en base a sus necesidades particulares. ¿Por qué esta última afirmación? Porque Lecor —en torno al cual se había formado el conocido como Club del Barón, compuesto por miembros de la elite política oriental que lo apoyaron desde $1817^{38}$ — junto a Durán promovieron la celebración de un Congreso representado en su mayoría por miembros afines políticamente al Barón con el fin de promover la incorporación formal de la provincia a la monarquía portuguesa. Siguiendo los planes de Lecor, el Congreso - posteriormente conocido con el nombre de Congreso Cisplatino- resolvió en el mes de agosto de 1821 la unión del territorio al Reino Unido de Portugal, Brasil y Algarve.

La formalización de esta incorporación es muy significativa. En primer lugar, la Provincia Oriental pasó a conocerse con la nueva denominación de Provincia Cisplatina, dando inicio al periodo en el que legalmente formó parte de los territorios de la monarquía bragantina. En segundo lugar, porque se trató de una incorporación inesperada y criticada a una y otra orilla del Atlántico y marcó los posteriores acontecimientos acaecidos en territorio oriental. A lo largo de los años veinte estallaron dos guerras en la provincia, la primera en 1822 (desencadenada por la declaración de independencia del Brasil) y la segunda en 1825 (entre las Provincias Unidas del Río de la Plata y el Imperio de Pedro I). En ambas, la facción que se opuso a la presencia de Lecor en la provincia hizo constante alusión a su ilegítima incorporación, no reconociendo la resolución de este Congreso Cisplatino.

37 Documentos Concernientes a la incorporación del Estado Cisplatino al Reino Unido de Portugal, Brasil y Algarve. Montevideo, 1821. AGNM, fondo de los Archivos Particulares, Caja 25, Carpeta 4. El historiador Juan E. Pivel Devoto llevó a cabo un exhaustivo análisis y traducción de los documentos cruciales para comprender el antes, el durante y el después de la celebración del Congreso Extraordinario. Pivel, 1937. Véase también Ferreira, 2009.

38 Las personas de confianza de Lecor y que conformaban el Club del Barón eran Juan José Durán, Jerónimo Pío Bianqui, Nicolás Herrera, Tomás García de Zúñiga y Fructuoso Rivera. Castellanos, 1986. Una vez instalado Lecor en el poder, además, practicó una política de concesión de títulos y condecoraciones y fomentó casamientos entre los militares que componían sus tropas con mujeres orientales de destacadas familias. Él mismo contrajo matrimonio con Rosa Maria Josefa Herrera de Basavilbaso. Para atender a la política que Lecor siguió en la Provincia Oriental con el fin de ganarse la adhesión o el apoyo de la población véase Ferreira, 2007. 
Dos proyectos políticos distintos, el de Silvestre Pinheiro Ferreira y Lecor, para la ahora Provincia Cisplatina, los cuales conllevaban también pretensiones distintas. Por su parte, el ministro portugués esperaba la declaración de independencia del territorio porque desde el mismo mes de abril de 1821 había mantenido una relación epistolar con el gobierno madrileño y con el bonaerense con la finalidad de apaciguar las tensiones y fomentar un acuerdo político-militar, la participación conjunta de la monarquía hispánica, la monarquía bragantina y los territorios del Cono Sur americano $^{39}$, lo que a partir de 1822 llamó la Familia Hispano-Lusitana ${ }^{40}$. Se trataba de un intento por constituir una confederación ultramarina compuesta por las Provincias Unidas del Río de la Plata, Brasil, Portugal y España en la que se comprometerían a mantener relaciones comerciales y a proteger sus respectivos gobiernos liberales ante la amenaza que la Santa Alianza representaba para el sur de Europa y América en estos inicios de los años veinte. El desalojo de las fuerzas portuguesas de la Provincia Oriental era crucial para que pudiese prosperar este entendimiento, pues el gobierno de la ciudad de Montevideo era reclamado tanto por los españoles como por los bonaerenses. Por este motivo, el ministro se comprometió a que el Congreso declararía la independencia tras lo cual, las tropas de la División de Voluntarios Reales desalojarían la capital oriental ${ }^{41}$.

Silvestre Pinheiro Ferreira pidió a Lecor que le mantuviese informado de todo lo ocurrido en Montevideo. No obstante, la relación entre ambos en los meses que siguieron a la celebración del Congreso no fue fluida ${ }^{42}$, y a Europa llegaron antes los rumores sobre la incorporación que la corroboración de la misma por parte de Lecor. A principios del mes de diciembre el ministro portugués escribió al Barón de la Laguna mostrándole su descontento ante la incorporación decretada por el Congreso Cisplatino ${ }^{43}$. La resolución de los diputados orientales causó malestar en los tres gobiernos que iban a estar implicados en esta confederación impulsada por el ministro. El bonaerense y el español mostraron desconfianza hacia las promesas de Silvestre Pinheiro Ferreira por asegurar una independencia que finalmente no se produjo ${ }^{44}$. Por su parte el ministro portugués mostró una gran desilusión y enfado hacia Lecor. En primer lugar, por la falta de noticias desde Montevideo, lo que había alimentado rumores y la inquietud de los gobiernos sobre lo ocurrido al respecto. En segundo lugar, porque Lecor fue acusado a una y otra orilla del Atlántico de intervenir en la elección de los diputados al Congreso y por tanto, alterar la resolución final del mismo favoreciendo la incorporación. Pinheiro Ferreira temió que la opinión pública pensase que él mismo estaba también involucrado en los actos del Barón, por lo que le pidió que desmintiese que hubiese recibido directrices paralelas a las enviadas por los medios oficiales que lo animasen a impulsar la unión de la provincia ${ }^{45}$. (en adelante ANTTL), MNE, libro 622. Véase también Frega, 2015a.

40 Carta del ministro Silvestre Pinheiro Ferreira. Lisboa, 16-VI-1822. ANTTL, MNE, libro 622.

41 Carta del ministro Silvestre Pinheiro Ferreira. Lisboa, 18-VII-1821. ANTTL, MNE, libro 622.

42 Correspondencia entre Silvestre Pinheiro Ferreira y Lecor. Lisboa, 3-XI-1821. ANTTL, MNE, libro 622.

43 Correspondencia entre Silvestre Pinheiro Ferreira y Lecor. Lisboa, 3-XII-1821. ANTTL, MNE, libro 622.

44 Silvestre Pinheiro Ferreira. Correspondência recebida. 1821. AHIRJ, lata 172, maço 3, pasta 4.

45 Correspondencia entre Silvestre Pinheiro Ferreira y Lecor. Lisboa, 22-XII-1821. ANTTL, MNE, libro 622. Para leer más sobre la relación epistolar que mantuvieron Silvestre Pinheiro Ferreira y el general Carlos Federico Lecor, así como las consecuencias que la incorporación de la provincia tuvo en las relaciones diplomáticas, véase Martínez Renau, 2018. 
En contraposición a la idea que Silvestre Pinheiro Ferreira tenía sobre la celebración del conocido como Congreso Cisplatino, se encontraban las pretensiones de Lecor. El Barón de la Laguna aspiraba a conseguir la incorporación en vistas, apuntó el historiador Pivel Devoto, de unir la provincia al Brasil cuando este declarase su independencia de Portuga ${ }^{46}$, aspecto que, aunque en 1821 no era todavía una realidad, sí se especulaba sobre el camino que seguiría el territorio americano cuando el rey João VI regresase a Lisboa. Para conseguir su propósito, ordenó a Juan José Durán que escribiese la normativa a seguir para la elección de los diputados del Congreso evitando la influencia de las distintas facciones. De este modo, podemos reparar, por ejemplo, en aquellos que fueron elegidos para representar a la ciudad de Montevideo. Los cuatro miembros (Juan José Durán, Dámaso Antonio Larrañaga y Tomás García de Zúñiga fueron elegidos diputados, Jerónimo Pio Bianqui acudió al Congreso como síndico procurador general de la ciudad) pertenecían al círculo de confianza de Lecor.

Durante el mes de junio - un mes antes de la apertura del Congreso- el Barón de la Laguna mantuvo correspondencia con Marcos de Noronha e Brito, octavo Conde dos Arcos que desde el mes de abril de 1821 ejercía de ministro y secretario de Estado de los Negocios del reino y extranjero en el Brasil. En estas cartas, en las que Lecor describía el estado de la provincia, mostraba su convencimiento de que los diputados al Congreso se inclinarían por la incorporación al Reino Unido de Portugal, Brasil y Algarve ${ }^{47}$, como finalmente ocurrió. La máxima autoridad de la Provincia Oriental mostraba una gran certeza de que el Congreso resolvería la unión, cuando este todavía no había abierto sus puertas.

Cuando en el mes de diciembre le llegó a Silvestre Pinheiro Ferreira la confirmación de la incorporación, le exigió explicaciones a Lecor ${ }^{48}$. En el mes de enero de 1822, en una carta que el Barón escribió a José Joaquín Monteiro Torres se excusaba sobre las decisiones tomadas en Montevideo y le adjuntó los documentos relativos a la organización y celebración del Congreso Extraordinario. El Barón de la Laguna se defendió a través de este escrito de las acusaciones que desde Europa y publicadas en la prensa bonaerense lo acusaban de haber intervenido en la elección de los diputados, tildando por ello la resolución final del Congreso de ilegítima. Justificó su actuación alegando que el documento enviado por Silvestre Pinheiro Ferreira contenía información orientativa sobre el modo de proceder, y que no se trataba de pautas explícitamente detalladas, sino órdenes que debían aplicarse "cuándo fuese posible"49. De este modo, la lejanía geográfica entre Montevideo y el gobierno portugués, establecido en Lisboa, impedía que pudiese preguntar cualquier cuestión relativa al mismo, por lo que junto a Juan José Durán adaptaron las indicaciones dadas a la realidad política de la provincia (número total de habitantes, modo de organización del proceso electoral, etc. $)^{50}$. A todo ello se sumaba una tercera problemática, ligeramente nombrada más arriba, la heterogeneidad de opiniones relativas a la presencia portuguesa en la provincia, habiendo facciones abiertamente contrarias a la autori-

\footnotetext{
$46 \quad$ Pivel, 1937.

47 Carta de Lecor. Montevideo, 1821. Arquivo Nacional [Brasil] (en adelante ANRJ), Coleção Cisplatina, 1A.COD.546.VOL.01, documento 55.

48 Correspondencia entre Silvestre Pinheiro Ferreira y Lecor. Lisboa, 22-XII-1821. ANTTL, MNE, libro 622.

49 Carta de Lecor a José Joaquín Monteiro Torres. Montevideo, 1822. AHIRJ, coleção Provincia Cisplatina, libro 309/4/10, documento número 2. Transcrito en Pivel, 1937: 247-256.

50 Ibídem.
} 
dad de Lecor. El capitán general trató de evitar la participación en el Congreso de los "enemigos del buen orden" 51 . Con esta declaración, evidenciaba dos cuestiones. La primera, admitió su intervención para evitar la representación en el Congreso de determinadas facciones políticas. En segundo lugar muestra que, a pesar de que un sector de la elite político-económica se posicionó a favor de la entrada portuguesa en Montevideo, no recibieron el apoyo unánime de la población oriental, como más tarde se vio en los dos conflictos bélicos que sufrió la provincia.

Los diputados al Congreso formalizaron la incorporación a la monarquía liberal portuguesa bajo veintidós condiciones, la primera de las cuales definía el territorio como "un Estado diverso de los demás del Reino Unido" y la tercera, que gozaría "del mismo rango que los demás de la monarquía y tendrá desde ahora su representación en el Congreso Nacional" 52 . Se constituía la Provincia Cisplatina bajo unos requisitos que demandaban y reconocían un grado de autonomía para el territorio que no llegó a materializarse en su totalidad, pues el gobierno lusobrasileño entendió la incorporación como la unión de la provincia al Reino del Brasil.

Desde el momento mismo de organización y celebración del Congreso la prensa porteña, como los periódicos El Argos de Buenos Aires o la Gaceta de Buenos Aires, denunciaron el proceso de elección de los diputados y manifestaron su oposición al acto de incorporación ${ }^{53}$. Como hemos visto, la decisión final del Congreso creó un clima de desconfianza y malestar entre Lecor y Silvestre Pinheiro Ferreira, pero también supuso un punto de inflexión en las relaciones diplomáticas entre el ministro portugués, el gobierno español en Madrid y el gobierno de Buenos Aires, a quienes Silvestre Pinheiro Ferreira les había prometido, meses antes, el desalojo portugués de la capital oriental ${ }^{54}$.

\section{1822. Un año controvertido}

La Cisplatina había sido integrada a la monarquía constitucional lusa y por ello, Lecor indicó que debía "procederse constitucionalmente a la elección de diputados a las Cortes Generales, luego que S.M. haya sido informado de este acto de incorporación a la monarquía portuguesa" "55. El 16 de noviembre de 1821, Tomás García de Zúñiga, síndico procurador, nombró a Lucas José Obes — abogado con una destacada trayectoria política - procurador del Estado Cisplatino cerca de S.M.F. y de las Cortes de Lisboa $^{56}$. El 13 de febrero de 1822, Obes salió de Montevideo junto al brigadier Feliciano Telles de Castro Aparicio ${ }^{57}$ para dirigirse a Lisboa e informar a las Cortes de lo resuelto en el Congreso Cisplatino, aunque no llegó a desembarcar en Europa, pues a la altura de Río Grande la corbeta se dirigió a Rio de Janeiro. Aquí se hizo

\footnotetext{
51 Ibídem.

52 Actas Congreso Cisplatino, 1821. Montevideo, 31-VII-1821. AGNM, fondo del Ex Archivo y Museo Histórico Nacional. I- Álbumes, Actas y Protocolos, libro 18. Transcritas en Pivel, 1937: 141-208.

53 Para profundizar en la denuncia que la prensa porteña hizo sobre la celebración del Congreso Cisplatino véase Ferreira, 2007: 215-232. Para atender, además, a la prensa montevideana de principios de los años veinte, véase Winter, 2017b, González, 2018.

54 Ferreira, 2007: 232-238. Martínez Renau, 2020: 23-48.

55 Actas Congreso Cisplatino, 1821. Montevideo, 31-VII-1821. AGNM, fondo del Ex Archivo y Museo Histórico Nacional. I- Álbumes, Actas y Protocolos, libro 18, transcrito en Pivel, 1937: 191-194.

56 Pivel, 1937.

57 Campos, 1972: 372.
} 
entrega de un oficio a Lucas José Obes en el que se le ordenaba que se quedase en la ciudad. Este documento, bajo el carácter de "reservado" estaba escrito por Tomás García de Zúñiga y fechado días antes de que la corbeta saliese de Montevideo. En él le daba indicaciones sobre el modo de proceder ante el príncipe regente don Pedro, a quien debía presentar sus respetos y detallar el estado en el que se encontraban "estos pueblos" ${ }^{\text {" }}$. Le pedía, también, que le informase de lo hablado tras reunirse con el príncipe.

Obes contestó en el mes de marzo y se mostró sorprendido por el cambio de rumbo que había tomado la corbeta y por las directrices que lo llevaron a desembarcar en Rio de Janeiro. Aun así, tildó su arribada a la ciudad como uno de "los sucesos más prominentes de esta época terrible en un aspecto y halagüeña en otro, por donde empieza, según mi juicio, a cimentarse la libertad y la grandeza de los Brasiles"59. A pesar del visible asombro que mostró en su escrito, el historiador Pivel Devoto apuntó que este conocía de antemano que tras su salida de Montevideo no se dirigía a Portugal sino a Brasil, y que se trataba de un plan previamente pactado entre Lecor y Obes según el cual, el procurador del Estado buscaría el acercamiento al gobierno de don Pedro mientras era testigo de las políticas que planteadas por el príncipe y sus ministros vaticinaban su declaración de independencia. Por su parte, Aparicio sí se dirigiría a Lisboa, donde se presentaría ante las Cortes ${ }^{60}$.

En este mismo escrito, Obes detallaba su reunión con don Pedro y sus ministros dándole a Lecor valiosa información sobre los ánimos políticos en la Corte en Rio de Janeiro. En él transcribía las palabras que el gobierno del Brasil le había transmitido, que podemos reunir en tres ideas. La primera, que desde la ciudad carioca estaba gestándose, ya a principios del año 1822, la ruptura del Reino Unido de Portugal, Brasil y Algarve. En segundo lugar, que el futuro Estado del Brasil sería liberal, regido por una Constitución. Y en último lugar, siendo esta una de las cuestiones que más interesaba al Barón de la Laguna, don Pedro reconocía la incorporación de la Cisplatina y nombró a Obes su consejero ${ }^{61}$. Eran estas, en palabras del mismo Obes, las "preciosas ideas que yo tuve la honra de recoger para transmitir a VS. no como un elogio sino como una muestra de lo que promete y tienen derecho a esperar estos pueblos del Augusto Príncipe que en mi presencia ha dicho"62. De este modo, Lucas José Obes fue posteriormente representante de la Cisplatina en Rio de Janeiro y mantuvo una relación epistolar constante tanto con las autoridades montevideanas como con Nicolás Herrera, el marido de su hermana Consolación Obes, con quién bien se ponían al corriente de sus asuntos personales como debatían juntos sobre el estado político-económico de la provincia.

58 Órdenes de Tomás García de Zúñiga a Lucas José Obes. Montevideo, 1822. AGNM, fondo de los Archivos Particulares, caja 15, carpeta 9, documento 1. Fechado el día 9 de febrero de 1822, cuatro días antes de que la corbeta Lecor saliese de Montevideo con Lucas José Obes y Feliciano Telles de Castro Aparicio

59 Reservado. Rio de Janeiro, 1822. AGNM, fondo de los Archivos Particulares, caja 15, carpeta 9, documento 4.

60 Pivel, 1937: 41-42. Esta idea puede observarse también en un documento escrito en 1823 en el que se detallaban los acontecimientos ocurridos en Montevideo desde la entrada portuguesa hasta el mes de octubre de ese año veintitrés. En él puede leerse: "que el Barón quería entenderse con las Cortes por vía del general Aparicio, y con S.M.F. por medio del síndico!!!” (las exclamaciones son del documento original). Prespectiva do Estado Cisplatino desde a sua occupação pelas armas de S.M.F. até Outubro de 1823. 1823. ANRJ, coleção cisplatina, 1A.COD.546.VOL.03, documento 280.

61 Respuesta de Lucas José Obes a Tomás García de Zúñiga. Rio de Janeiro, 1822. AGNM, fondo de los Archivos Particulares, caja 15, carpeta 9, documento 4.

62 Ibídem. 
Las actas de las sesiones de las Cortes de Lisboa muestran el distanciamiento político que experimentaron Portugal y Brasil desde los últimos meses del año 1821. En el mes de octubre, las Cortes enviaron a don Pedro un decreto por el que le ordenaban que regresase a Europa, ante el cual, el príncipe se negó y contestó a principios del mes de enero de 1822 que permanecería en Rio de Janeiro. De este modo, procedió a organizar el gobierno que continuaría junto a él en la parte americana del todavía Reino Unido y a la instalación de una Asamblea Legislativa ${ }^{63}$. Las autoridades políticas de Montevideo se posicionaron junto al príncipe regente. En el mes de mayo, Lucas José Obes envió un comunicado al ministro José Bonifácio de Andrade e Silva en el que le indicaba que "La Provincia Cisplatina me ordena que felicite a S.A.R. el príncipe regente por la magnánima solución de permanecer entre estos sus amados pueblos del Brasil" ${ }^{\prime}$. A lo largo del año 1822 el gabinete de don Pedro fue trazando el proyecto independentista. A la par, también las autoridades desde Montevideo se movilizaron al respecto.

\subsection{Montevideo, ¿de Portugal o del Brasil? La guerra de independencia en la Cisplatina}

José Bonifácio de Andrada e Silva envió a Montevideo las instrucciones para la elección de los diputados que acudirían a la Asamblea en representación de las distintas provincias ${ }^{65}$, que fueron incluso, traducidas al castellano. A pesar de ello, el Barón de la Laguna y Tomás García de Zúñiga tomaron la decisión de no hacer públicos los decretos que llegaban de Rio de Janeiro por lo que mostrándose cautelosos, no se

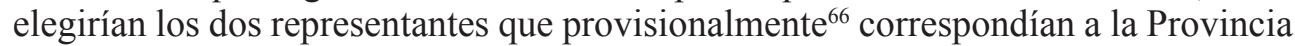
Cisplatina ${ }^{67}$. El motivo que condujo a la decisión del capitán general y del síndico procurador fue las diferencias en torno a la cuestión brasilera entre Lecor (y el Club del Barón) y la División de Voluntarios Reales que permanecía en Montevideo y que en su mayoría se mostraron contrarios a la posible declaración de independencia del Brasil, por lo que el capitán general decidió que no publicaría los distintos decretos hasta que las tropas portuguesas no embarcasen de la capital oriental hacia Portugal. Comenzaron de este modo unos meses en los que Lecor mantuvo correspondencia constante con José Bonifácio de Andrada e Silva, estando al corriente de los acontecimientos de Rio de Janeiro, al mismo tiempo que disimulaba públicamente su opinión y sus pretensiones políticas para no generar conflicto en la provincia.

El Consejo Militar de la División de Voluntarios Reales lanzó una proclama en la que mostraba su apoyo a las Cortes lisboetas y al rey João VI, y desaprobaba la incorporación de la Cisplatina al Brasil, la presencia de Obes en Rio de Janeiro como representante de la provincia, y las aspiraciones independentistas de don Pedro:

\footnotetext{
63 Slemian, 2009: 74.

${ }^{64}$ Comunicado de Lucas José Obes. Rio de Janeiro, 1822. ANRJ, coleção cisplatina, 1A.COD.546.VOL.02, documento 9 .

65 Real Decreto. En que se manda convocar una Asamblea General Constituyente y Legislativa para el Reino del Brasil. Rio de Janeiro, 1822. Biblioteca Brasiliana Guita e José Mindlin [Brasil] (en adelante BBGEJM), coleção cisplatina, M1H00950.

66 Dada la urgencia con la que fue convocada e instalada la Asamblea Legislativa del Brasil, se asignó un número provisorio de diputados que se readaptaría cuando se contase con el censo actualizado.

${ }^{67}$ Carta de Tomás García de Zúñiga al ministro de Estado y de los Negocios del Reino. Montevideo, 23-VIII-1822. AGNM, fondo de los Archivos Particulares, caja 15, carpeta 9.
} 
El Reino Unido, Europa y el mundo entero debe conocer que no tenemos parte en tan ruinosos planes, que nuestro pensar es el mismo que en el medio de transportes de alegría manifestamos, y juramos en el siempre memorable día 20 de marzo del año pretérito; que respetamos la nación, que amamos el rey, y que sabemos ser lo que debemos ${ }^{68}$.

Este documento, con fecha del 28 de junio de 1822, contenía la firma de Lecor por ser el presidente del Consejo, seguida de la de Álvaro da Costa de Souza Macedo, que ocupaba el cargo de vicepresidente. Unos días más tarde, el 1 de julio, el Barón de la Laguna se comunicó con José Bonifácio de Andrada e Silva para excusarse y explicarle los motivos por los que había firmado la proclama. Aseguraba que le fue propuesta por el Consejo Militar, y que a pesar de que trató de evitar que fuese publicada, no pudo porque:

El Consejo Militar exigió y a la que no me pude negar porque de lo contrario, la División tomaría las armas para manifestar con ellas sus sentimientos, para declarar que el Dr. Obes no debía quedarse en Río de Janeiro, tratando una Comisión que solo a las Cortes de Lisboa cumple entender [...] y para apuntarme a mí partidista del Brasil ${ }^{69}$.

Además, le pedía también al ministro que decretase la salida de Montevideo de las tropas que formaban la División, ahora bien, también aconsejaba que, si sus hombres evacuaban la capital, debían enviarse nuevas fuerzas para evitar que pudieran materializarse las aspiraciones de dominación extranjera sobre la Provincia Cisplatina o que bien, las facciones internas contrarias a la presencia lusobrasileña encontrasen la oportunidad para rebelarse ${ }^{70}$.

Las denuncias y protestas sobre el modo de proceder de Lecor y sus hombres de confianza, no solamente desde la División de Voluntarios Reales, sino también desde la prensa local, continuaron durante los siguientes meses del año veintidós. Pusieron en duda la fidelidad del Barón de la Laguna al monarca João VI, pero también criticaron sus maniobras políticas para conseguir la anexión de la Cisplatina al Brasil ${ }^{71}$. La táctica empleada por la que Lucas José Obes arribó —y permaneció- en Rio de Janeiro fue motivo de debate. Se cuestionó si el síndico Tomás García de Zúñiga poseía la potestad política requerida para nombrar a Obes procurador de la Cisplatina y dirigir su cometido en el Brasil. Por ende, se atacó la validez de la llamada misión Obes, por la que este buscaba el acercamiento con el gobierno de don Pedro ${ }^{72}$.

La vigésima condición acordada por los diputados orientales en el Congreso Cisplatino para pactar la incorporación de la provincia a la monarquía bragantina contemplaba la presencia de la figura del síndico procurador general del Estado, destinada a garantizar el cumplimiento de las veintidós cláusulas propuestas en el

68 Documentos referentes ao Conselho militar da Divisão de Voluntários de el Rey. Montevideo, 1822. AHIRJ, lata 194, maço 04, pasta 20, III Coleções especiais, 30- Documentação do Ministério anterior a 1822.

69 Correspondencia de Lecor a José Bonifácio de Andrada e Silva. Montevideo, 1-VII-1822. AHIRJ, libro $306 / 4 / 10$.

70 Correspondencia de Lecor a José Bonifácio de Andrada e Silva. Montevideo, 1822. ANRJ, coleção cisplatina, caixa 977, documento 2 .

71 El Pacifico Oriental de Montevideo, n 27, 4-VII-1822.

72 Ibídem. 
Congreso. Por pluralidad de votos entre los asistentes, Tomás García de Zúñiga fue asignado para el cargo ${ }^{73}$. En las mismas actas del Congreso Cisplatino constaba que se debería proceder "constitucionalmente a la elección de Diputados a las Cortes Generales, luego que Su Majestad haya sido informado de este acto de incorporación a la monarquía portuguesa constitucional" 74 . Por este motivo, a García de Zúñiga se le acusaba en 1822 de haber nombrado personalmente a Obes procurador general sin que se hubiesen seguido las instrucciones oficiales para ello, y que este último hubiese desembarcado en Rio de Janeiro como representante de la Cisplatina, en busca de la unión al Reino del Brasil, sin que se conociese en Montevideo la respuesta del rey João VI al respecto de la incorporación ${ }^{75}$.

El día 11 de julio el cabildo de la capital discutió la cuestión sobre si debían remitir una protesta formal al gobierno por la misión Obes ${ }^{76}$. Este debate se debía al descontento que Gabriel Antonio Pereyra (alcalde provincial) y Cristóbal Echevarriarza (regidor defensor general de menores) mostraron sobre el procedimiento de las autoridades lecoristas. Pidieron "representar por oficio reservado al superior gobierno sobre la nulidad de la elección que el síndico procurador general de este Estado d. Tomás García de Zúñiga había hecho en el Dor. d. Lucas José Obes, cerca de S.A.R el príncipe regente del Brasil" "77. Los miembros del cabildo votaron en su mayoría negativamente la reclamación que presentaban Pereyra y Echevarriarza, por lo que "se mandó romper el dispuesto oficio, como en el acto se verificó"78. Tomás García de Zúñiga se defendió ante unas acusaciones que no cesaron ni a lo largo del año 1822 ni de los meses siguientes de 1823. En un oficio que envió al cabildo de la ciudad de Maldonado calificaba a los autores de los escritos publicados en la prensa como "aquellos hombres perversos que esperan labrar sus fortunas sobre las ruinas del orden y de la tranquilidad pública” y los acusaba de poner en

movimiento todos los resortes de la calumnia, de la mordacidad y de la intriga para dividir las autoridades y desacreditar a los magistrados y a la administración y promoviendo innovaciones peligrosas y contrarias a las resoluciones sancionadas por el Congreso Extraordinario de los representantes de este Estado, poner en convulsión los pueblos y sumir el país en todas las desgracias de la revolución ${ }^{79}$.

El síndico señalaba también que "llevan la animosidad hasta el punto de atribuirme un criminal exceso en el ejercicio de los poderes que me confirió el Honorable Congreso de esta provincia para promover y defender sus derechos políticos, civiles y constitucionales" ${ }^{\prime 2}$. Las acusaciones dirigidas a Tomás García de Zúñiga no mermaron su poder, y tampoco afectó a su relación con Lecor. Continuó como hombre

\footnotetext{
73 Actas Congreso Cisplatino, 1821. Montevideo, 31-VII-1821. AGNM, fondo del Ex Archivo y Museo Histórico Nacional. I- Álbumes, Actas y Protocolos, libro 18. Transcritas en Pivel, 1937: 141-208.

74 Ibídem. Transcrito en Pivel, 1937: 198.

75 El Pacifico Oriental de Montevideo, $\mathrm{n}^{\circ} 27,4$-VII-1822.

76 Campos, 1972: 360. Véase también Acuerdos del extinguido cabildo de Montevideo, acta del día 11-VII-1822.

77 Acuerdos del extinguido cabildo de Montevideo, acta del día 11-VII-1822.

78 La historiadora Martha Campos Thevenin de Garabelli señaló que el voto contrario a la expedición del oficio por parte de la mayoría de los miembros del cabildo se debió seguramente al temor a la reacción del síndico. Campos, 1972: 362-365.

79 Defensa de Tomás García de Zúñiga. Montevideo, 16-VII-1822. AGNM, fondo del Ex Archivo y Museo Histórico Nacional, caja 14.

80 Ibídem.
} 
de confianza del capitán general posicionándose en favor del ejército imperial del Brasil cuando estalló el conflicto bélico a finales de 1822 .

Mientras tanto, a lo largo del año de 1822, Lecor insistió, reiteradamente, en la necesidad de que los miembros de la División de Voluntarios Reales saliesen definitivamente de la ciudad de Montevideo. Su presencia dificultaba la consecución de sus propósitos, al mismo tiempo que la llegada de noticias sobre la próxima proclamación de independencia del Brasil causaba revuelo en la capital oriental y ponía el foco de la opinión pública sobre las decisiones de Lecor. A la abierta oposición que el Consejo Militar de la División mostró sobre los planes independentistas de don Pedro, se sumaron las distintas rebeliones que desde el año anterior de 1821 habían protagonizado sus hombres. El 20 de marzo de 1821, bajo el lema "patria y paga" las tropas portuguesas exigían el regreso de los hombres a Portugal y el pago de los atrasos en sus sueldos ${ }^{81}$. Desde entonces, protagonizaron distintos actos de desobediencia en los que exigían el cumplimiento de sus peticiones. Ante ello, el Barón advertía que "si la pretensión de paga no tiene lugar, porque yo la estoy satisfaciendo, y la de patria está en pie, y no puede ser satisfecha por mí, me pondrá en grandes compromisos y tendrá perniciosa influencia contra los intereses de la nación" ${ }^{2}$. Dada la delicada coyuntura vivida en Montevideo, el ministro José Bonifácio de Andrada e Silva propuso, en el mes de marzo de 1822, la disolución de las tropas, que representaban el "espíritu de desorden y anarquía" 83.

Cinco meses más tarde, el 14 de agosto, José Bonifácio envió diversos oficios en nombre del príncipe regente - a distintas autoridades en Montevideo. El primero era para el Barón de la Laguna, el segundo iba dirigido al síndico Tomás García de Zúñiga y el último, al jurista Nicolás Herrera. En todos ellos daba las órdenes a seguir ante el inicio de una guerra en la Cisplatina por la independencia del Brasil. El escrito para Lecor anunciaba el cese del Consejo Militar de la División de Voluntarios Reales "por la ilegalidad de su convocación y por todos sus actos ulteriores" ${ }^{84}$. En el caso de que las tropas no obedecieran las órdenes, instó al capitán general a que saliese de Montevideo, que se reuniese en la campaña con el síndico y con el brigadier Manoel Marques y que ejerciesen las medidas oportunas para que el Consejo y las tropas se plegasen a sus exigencias ${ }^{85}$. El oficio a Tomás García de Zúñiga era algo más detallado, pues lo animaba también a salir de Montevideo, a establecerse en la campaña, reunir al ejército y junto al brigadier Manoel Marques, dirigir a las tropas a comenzar un sitio a la ciudad de Montevideo "impidiendo la entrada de todos los víveres" 86 . A Nicolás Herrera, sin embargo, le envió un oficio en el que contemplaba diversos escenarios. Le hizo llegar los documentos enviados a Lecor y a Tomás García de Zúñiga, por lo que el jurista conocía también las pautas a seguir ante la desobediencia de la División de Voluntarios Reales, pero además, el ministro planteaba una segunda posible insurrección, la del capitán general Lecor: le mandaba por ello actuar "en el caso de que las referidas tropas no obedezcan las órdenes que le han sido expedidas para sus bajas y pronto embarque, o cuando el Barón de la Laguna deje de cumplir

81 Los historiadores Ana Frega y Fábio Ferreira profundizan en los motines y reclamas de la División de Voluntarios Reales en Frega, 2015a, Ferreira, 2012.

82 Carta de Lecor. Montevideo, 1822. AHIRJ, libro 309/4/10, documento XXXI.

83 Frega, 2015b: 57-90.

84 Carta de José Bonifácio de Andrada e Silva a Lecor. Rio de Janeiro, 14-VIII-1822. AGNM, fondo de los Archivos Particulares, caja 15, carpeta 9.

85 Ibídem.

86 Ibídem. 
las que le son dirigidas en el mencionado decreto o venga a unirse con los rebeldes" $"$. José Bonifácio de Andrada e Silva no explicitaba el motivo que lo llevaba a desconfiar de Lecor. Que en el mes de junio hubiese subscrito la denuncia escrita por el Consejo Militar de la División de Voluntarios Reales en la que se denunciaban los preparativos de la independencia del Brasil pudo ser, tal vez, uno de los motivos que llevó al ministro a pensar que el Barón no obedecería sus órdenes. Otro de ellos pudo ser la demanda que el Barón de la Laguna hizo en el mes de febrero de 1822, cuando excusándose en las intrigas e inestabilidad política de la ciudad de Montevideo, pidió que "por la distancia de esa Corte, y por la demora de los viajes, no sea fácil figurar todas las hipótesis, que ciertos accidentes pueden hacer variar mucho, y que sería necesario proveer, tal vez que conviniese mucho que Su Alteza Real me autorizase en sus órdenes soberanas para yo acomodar la ejecución de ellas al tiempo y forma que imperiosamente pidiesen las causas" "88. Lecor mostró, a lo largo de la década de 1820 una predisposición a ampliar los poderes que su cargo político le permitía.

A pesar de que José Bonifácio de Andrada e Silva había decretado el embarque de las tropas de la División de Voluntarios Reales de la capital oriental, las Cortes de Lisboa, en el mismo mes de agosto del que fechan los oficios del ministro a las autoridades de Montevideo, debatían la conveniencia de que las fuerzas portuguesas evacuaran o no la ciudad. El coste económico que el gobierno lusobrasileño invertía en ellas y las diversas insubordinaciones protagonizadas desde 1821 eran algunos de los motivos presentados por los diputados en las Cortes en defensa de su salida de Montevideo. Aun así, también planteaban si estas debían volver a Europa o por el contrario, destinarlas a otros dominios donde pudieran "mejor defender la integridad de la monarquía"89. La rebelión en Montevideo, la próxima declaración de independencia del Brasil y la amenaza que suponía la Santa Alianza sobre los gobiernos liberales español y portugués planteaban la idoneidad de si debían las tropas quedarse en América o regresar a Europa. Los diputados en las Cortes votaron favorablemente a autorizar la salida de la División de Voluntarios Reales de la Provincia Cisplatina, aun así, las cuestiones militares eran competencia del poder ejecutivo, por lo que, en última instancia, debía ser el gobierno quién decidiese sobre la cuestión ${ }^{90}$.

La proclamación del emperador Pedro I inició un conflicto bélico en la Provincia Cisplatina. En la ciudad de Montevideo permaneció la División de Voluntarios Reales, que se proclamó fiel a los derechos de João VI sobre los territorios americanos. En la campaña se estableció el ejército pro-brasileño. El 22 de septiembre de 1822 , Nicolás Herrera informaba a José Bonifácio de Andrada e Silva que, siguiendo sus órdenes, salió de Montevideo junto a Tomás García de Zúñiga en dirección a Canelones donde se reunieron con el brigadier Manuel Marquez de Sousa. Herrera le confirmaba al ministro que también el Barón de la Laguna se había adherido al bando imperial a quien "felizmente le hallamos muy dispuesto a dar el debido cumplimiento a los reales decretos de su alteza real" 91 tras lo cual, se asentaron en la villa de

87 Carta de José Bonifácio de Andrada e Silva a Nicolás Herrera. Rio de Janeiro, 1822. AGNM, fondo de los Archivos Particulares, caja 17, carpeta 1, documento 29.

88 Carta de Lecor. Montevideo, 7-II-1822. AHIRJ, libro 309/4/10.

89 Diario das Cortes geraes e extraordinarias da nação portuguesa, intervención del diputado Moura en la sesión del 23-VIII-1822.

$90 \quad$ Ibídem. Sesión del 23-VIII-1822.

91 Carta de Nicolás Herrera a José Bonifácio de Andrada e Silva. San José, 1822. ANRJ, coleção cisplatina, 1A.COD.546.VOL.02, documento 97. 
San José. En la capital quedó la División de Voluntarios Reales, que comandada por el brigadier Álvaro da Costa de Sousa Macedo actuó junto al cabildo de Montevideo que a finales del año de 1822 y durante el año de 1823 mostró una clara oposición a Lecor y aspiró a evitar el triunfo del ejército del Barón. Ambos tenían un enemigo en común, las tropas imperiales. Comenzaba una guerra de un año de duración, que terminó con la incorporación de la Provincia Cisplatina al recién proclamado Imperio de Pedro I a principios del año 1824.

Desde la capital, el cabildo buscó, junto a Álvaro da Costa, la intervención del gobierno de Buenos Aires en la guerra con la finalidad de que este les auxiliase económicamente o con el envío de refuerzos y material militar para suplir las carencias que les impedían imponerse al ejército imperial. Por su parte, el gobierno de Buenos Aires - que tenía intereses políticos sobre la provincia y había reclamado la pertenencia de esta a las Provincias Unidas del Río de la Plata - se negó a intervenir directamente en el conflicto tal y como le suplicaban los miembros del cabildo de Montevideo, pero sí trató de mediar en él al enviar a Rio de Janeiro a Valentín Gómez con el objetivo de pactar con el emperador Pedro I el fin de la guerra y la salida del ejército de la provincia ${ }^{92}$.

En el mes de mayo de 1823, los gobiernos de Buenos Aires, Corrientes y Entre Ríos enviaron conjuntamente al Barón un oficio en el que le demandaban que pusiese fin a las hostilidades y la desocupación del territorio por los ejércitos luso-brasileños ${ }^{93}$. La respuesta de Lecor está fechada en el mes de junio, en la que les advertía que "el Barón de la Laguna protege y no ataca a los pueblos de este Estado" y ponía en duda la autoridad de los tres gobiernos para intervenir en los asuntos políticos de la provincia. Mientras tanto, la secretaría de Estado de los negocios del Imperio confirmaba a Lecor que continuase con su "pericia militar, que emplease toda su energía para llevar a cabo esta importante empresa pero que estreche con el mayor rigor el asedio de la plaza de Montevideo y lo torne eficaz y decisivo"94.

La guerra continuó en la provincia hasta finales del año 1823. El 18 de noviembre el capitán general Lecor y representantes del brigadier Álvaro da Costa firmaron el armisticio que ponía fin al conflicto. Tras ello, la División de Voluntarios Reales desalojó finalmente Montevideo y el Barón de la Laguna recuperó la gobernación política de la Provincia Cisplatina. Restablecido el poder de Lecor en la capital, declaró nulas todas las resoluciones implantadas por el cabildo del año anterior, y aplicó medidas intransigentes contra aquellos sobre los que hubiese sospechas de oposición a su régimen.

\section{A modo de conclusión}

Los años veinte del siglo XIX comenzaron políticamente agitados a una y otra orilla del Atlántico. La proclamación de los nuevos gobiernos liberales en la península, tanto en España como en Portugal, puso la ciudad de Montevideo en el punto de

92 Para profundizar en el progreso de la guerra desde la ciudad de Montevideo y la participación y postura del cabildo de Montevideo al respecto, véase Campos, 1972 y 1978.

93 Oficio enviado a Lecor firmado por los gobiernos de Buenos Aires, Corrientes y Entre Ríos. 1823. AGNM, fondos de los Archivos Particulares, caja 15, carpeta 9, documento 51.

94 Órdenes dadas a Lecor. Rio de Janeiro, 1823. AGNM, fondo de los Archivos Particulares, caja 15, carpeta 9, documento 50 . 
mira. La capital oriental estaba gobernada por el general Lecor, aunque el monarca João VI insistía ante las potencias internacionales que se trataba de una ocupación temporal, no definitiva. Ante este complejo escenario, llegó a Montevideo la noticia sobre el triunfo de la Revolución de Oporto y la apertura de las Cortes Constituyentes en Lisboa. Fueron los regimientos de la División de Voluntarios Reales los que juraron el futuro texto constitucional luso, no lo hicieron, en este momento, los representantes del Cabildo de la capital. Seguramente, porque esto significaría contradecir las palabras del monarca portugués, reconocer la Provincia Oriental como parte del Reino Unido de Portugal, Brasil y Algarve y por tanto iniciar una disputa política con Fernando VII. La importancia que la ocupación y gobernación de la ciudad de Montevideo tuvo en las relaciones internacionales la evidencia no solamente la celebración y la repercusión que tuvo el Congreso Cisplatino sino también la correspondencia que el ministro portugués Silvestre Pinheiro Ferreira envió a los gobiernos de Madrid y Buenos Aires para la búsqueda de un acuerdo ultramarino en el que situaba el desalojo de la capital oriental como punto de partida de las negociaciones.

El trienio de 1820-1823 del que se ocupa este dossier, fue crucial en Montevideo para comprender la complejidad de la década hasta la declaración de independencia de la Provincia. En estos tres años, se constituyó en Provincia Cisplatina formalizando su incorporación a la monarquía liberal portuguesa y sufrió una guerra que terminó en 1824 con la incorporación del territorio al Imperio del Brasil. Ambos acontecimientos fueron motivo de protesta y disputa política y marcaron los acontecimientos de los años posteriores.

\section{Referencias bibliográficas}

Berbel, Márcia. A nação como artefato: Deputados do Brasil nas Cortes Portuguesas, 1821 1822. São Paulo: Hucitec, 1998.

— "Nación portuguesa, Reino de Brasil y autonomía provincial”. En Revolución, independencia y las nuevas naciones de América, coordinado por Rodríguez O., Jaime E. Madrid: Fundación Mapfre Tavera, 2005, 397-423.

- A constituição espanhola no mundo luso-americano (1820-1823). Revista de Indias, vol. $68, \mathrm{n}^{\mathrm{o}} 242$ (2008), 225-254.

— “Cádiz: una referencia en la Constitución del Imperio del Brasil”. En 1812 El poder de la palabra. América y la Constitución de 1812, coordinado por Chust, Manuel. Acción Cultural Española - Consorcio para la Conmemoración del II Centenario de la Constitución de 1812 - Barcelona: Lunwerg Editores, 2012, 247-251.

Campos Thevenin de Garabelli, Martha. La revolución oriental de 1822-1823. Su génesis, tomo I (1972) y tomo II (1978). Montevideo: Junta Departamental de Montevideo, Biblioteca “José Artigas", 1972.

Castellanos, Alfredo. La Cisplatina, la independencia y la república caudillesca, 1820-1838, tomo III. Historia Uruguaya. Montevideo: Ediciones de la Banda Oriental, 1986.

Ferreira, Fábio. "O general Lecor e as articulações políticas para a criação da Província Cisplatina: 1820-1822”. Dissertação de mestrado, Rio de Janeiro: Instituto de Filosofia e Ciências Sociais, Universidade Federal do Rio de Janeiro, 2007.

- "O Congresso Cisplatino e seus desdobramentos políticos no Brasil e na região do Prata". Estudios Históricos, nº 2 (2009), 55-71. 
- "O general Lecor, os Voluntários Reais, e os conflitos pela independência do Brasil na Província Cisplatina: 1822-1824”. Tese de doutorado, Universidade Federal Fluminense, Instituto de Ciências Humanas e Filosofia, Departamento de História, 2012.

Frasquet, Ivana. "La segunda oportunidad. La 'pacificación de las Américas' en el contexto constitucional de 1820. El caso de México". En La construcción del estado y la nación en España y México, editado por Suárez Cortina, Manuel - Pérez Vejo, Tomás. Santander: Universidad de Cantabria, 2010, 118-140.

Frega, Ana. "Guerras de independencia y conflictos sociales en la formación del Estado Oriental del Uruguay, 1810-1830”. Dimensión Antropológica, año 12, vol. 35 (2005), 25-58.

— "Alianzas y proyectos independentistas en los inicios del 'Estado Cisplatino'". En Historia regional e independencia del Uruguay. Proceso histórico y revisión crítica de sus relatos, coordinado por Frega, Ana. Montevideo: Banda Oriental, 2009, 19-63.

- "Ecos del constitucionalismo gaditano en la Banda Oriental del Uruguay". Trocadero, $\mathrm{n}^{\circ}$ 24 (2012), 11-25.

— "Las fronteras de la soberanía. Apuntes para un atlas de la Banda Oriental del río Uruguay en la primera mitad del siglo XIX”. En La subversión del orden por la palabra. Tiempo, espacio e identidad en la crisis del mundo ibérico. Siglos XVIII-XIX, coordinado por Fernández Sebastián, Javier - Suárez Cabal, Cecilia. Bilbao: Servicio Editorial de la UPV, 2015a, 219-239.

- "Proyectos políticos y faccionalismo militar. Ecos de la crisis de la monarquía portuguesa en Montevideo, 1820-1824”. Illes i Imperis, no 17 (2015b), 57-90.

Gil Novales, Alberto. El Trienio Liberal. Madrid: Siglo XXI, 1980.

González Demuro, Wilson. La prensa de Montevideo, 1814-1825. Imprentas, periódicos y debates públicos en tiempos de revolución. Montevideo: CSIC - Universidad de la República, 2018.

La Parra, Emilio. Fernando VII: un rey deseado y detestado. Barcelona: Tusquets editores, 2018.

Luque Azcona, Emilio José. Ciudad y poder: la construcción material y simbólica del Montevideo colonial (1723-1810). Sevilla: CSIC - Escuela de Estudios Hispano-Americanos - Universidad de Sevilla - Diputación de Sevilla, 2007.

Martínez Renau, Laura. “¿Independencia o unión? Proyectos políticos para la Banda Oriental: el Congreso Cisplatino de 1821”. En El tribunal de la soberanía. El poder legislativo en la conformación de los estados: América Latina, siglo XIX, coordinado por Irurozqui Victoriano, Marta. Madrid: Marcial Pons, 2020, 23-48.

Martínez Riaza, Ascensión. "Para reintegrar la nación. El Perú en la política negociadora del Trienio Liberal con los disidentes americanos, 1820-1824". Revista de Indias, vol. LXXI, $n^{\circ} 253$ (2011), 647-692.

Pimenta, João Paulo G. O Brasil e a América espanhola (1808-1822). Tesis Doctoral. São Paulo, 2003.

— “O Brasil e a 'experiência cisplatina' (1817-1828)". En Independência: História e Historiografia, organizado por Jancsó, István. São Paulo: FAPESP - Editora HUCITEC - Estudos Históricos, 2005, 755-789.

- Brasil y las independencias de Hispanoamérica. Castelló de la Plana: Publicacions de la Universitat Jaume I, 2007.

- Estado y Nación hacia el final de los imperios ibéricos. Río de la Plata y Brasil. 18081828. Buenos Aires: Editorial Sudamericana, 2011.

- La independencia de Brasil y la experiencia hispanoamericana (1808-1822). Santiago de Chile: DIBAM, 2017. 
Pivel, Juan E. El Congreso Cisplatino (1821). Repertorio documental seleccionado y precedido de un análisis. Montevideo: Imprenta "Siglo Ilustrado", 1937.

Ribeiro, Ana. Los tiempos de Artigas. Montevideo: Planeta, 2009.

- Los muy fieles. Leales a la corona en el proceso revolucionario rioplatense. Montevideo - Asunción. 1810-1820. Montevideo: Planeta, 2013.

Sánchez Gómez, Julio. "Brasil y Uruguay: dos procesos de independencia íntimamente relacionados”. En Las independencias iberoamericanas ¿un proceso imaginado?, editado por Bosco Amores, Juan. Bilbao: Universidad del País Vasco, 2009, 139-182.

— "Montevideo y la Constitución de Cádiz". En 1812 El poder de la palabra. América y la Constitución de 1812, coordinado por Chust, Manuel. Acción Cultural Española - Consorcio para la Conmemoración del II Centenario de la Constitución de 1812 - Barcelona: Lunwerg Editores, 2012, 207-213.

Slemian, Andréa. "Instituciones, legitimidad y [des]orden: crisis de la monarquía portuguesa y construcción del Imperio del Brasil (1808-1841)". En De las independencias a los estados nacionales (1810-1850). 200 años de historia, editado por Frasquet, Ivana - Slemian, Andréa. Madrid - Frankfurt: Iberoamericana Vervuert - Colección Estudios AHILA, 2009, 89-108.

- Sob o Império das leis. Constitução e unidade nacional na formação do Brasil (18221834). São Paulo: Editora Hucitec, Fapesp, 2009.

Vidal, Angel H. (dir.). Acuerdos del extinguido cabildo de Montevideo. Montevideo: Archivo General de la Nación, vol. 14, libros XVII y XVIII, 1941.

Winter, Murillo Dias. Imprensa periódica e a construção da identidade oriental. Província Cisplatina (1821-1828). Porto Alegre: Fi editora, 2017a.

- "Os negócios neste reino exigem atenção: apontamentos sobre a independência do Brasil na Província Cisplatina (1821-1824)”. En Belicosas fronteiras. Contribuições recentes sobre política, economia e escravidão em sociedades americanas (século XIX), organizado por Vargas, Jonas M. Porto Alegre: RS: Editora Fi, 2017b, 29-48. 